\title{
Leiomyosarcoma of the right ventricle extending into the pulmonary trunk
}

\author{
W Willaert, P Claessens, M Vanderheyden
}

\begin{abstract}
Primary leiomyosarcomas of the heart, particularly those affecting the right ventricle, are uncommon. A 70 year old woman presenting with the symptoms of progressive exertional dyspnoea and left sided pleuritic pain is presented. A leiomyosarcoma was diagnosed that originated in the right lateral ventricle wall, causing pulmonary outflow obstruction. Pathological analysis showed a neoplasm with a myxoid stroma, high mitotic activity, and nuclei expressing atypia. Immunohistochemical staining was found positive for vimentin and desmin. Seven months after complete surgical resection the tumour relapsed. This case illustrates the poor outcome, high relapse rate, and inefficiency of treatment associated with primary cardiac leiomyosarcomas. The current literature regarding incidence, diagnostic techniques, treatment strategies, and survival rates of this rare but terminal disease is reviewed.

(Heart 2001;86:e2)
\end{abstract}

Keywords: cardiac neoplasm; leiomyosarcoma; right ventricle

Leiomyosarcomas are an extremely small minority of primary cardiac tumours ${ }^{12}$ and are associated with an unfavourable outcome. They are an infrequent cause of ventricular outflow obstruction. Recent diagnostic techniques have led to earlier detection and have subsequently enhanced the potential for more effective management. Nonetheless the preferred treatment of surgical resection is considered palliative as metastasis and tumour relapse are frequent. Survival rates are poor and rarely exceed one year. ${ }^{3}$

We report a case of a 70 year old woman admitted with severe dyspnoea and left sided pleuritic pain. Diagnostic examination showed a mass in the outflow tract of the right ventricle that, after surgical resection and histological examination, proved to be a leiomyosarcoma.

\section{Case presentation}

A 70 year old woman was admitted to hospital because of progressive dyspnoea and left sided pleuritic pain. She had been well until two months before, when she experienced left sided thoracic pain radiating to the shoulder. The pain was accompanied by exertional dyspnoea (grade II) as well as by a non-productive cough.

The patient was a retired housecleaner and had never smoked. She had a remote history of metrorrhages surgically cured by a hysterectomy, as well as urinary incontinence caused by vesical prolapse. Although she had a family history of cardiac disease, she herself had never suffered from cardiac disease.

At admission her temperature was $36.6^{\circ} \mathrm{C}$, pulse was 100 beats/min and respiratory rate was 30 breaths/min. Blood pressure was 120/ $80 \mathrm{~mm} \mathrm{Hg}$. The oxygen saturation was $91 \%$ while the patient was at rest and breathing room air. No signs of right or left sided heart failure were present. Cardiovascular auscultation showed a split second heart sound as well as systolic ejection murmur in the upper sternal border. The lungs were clear and abdominal examination showed no abnormalities.

A chest $x$ ray showed a pronounced cardiomegaly as well as a slight prominent right hilus and broad mediastinum. Blood chemistry and ECG were within normal limits. Blood gases indicated hypoxaemia $(60 \mathrm{~mm} \mathrm{Hg})$ and hypocapnia $(30 \mathrm{~mm} \mathrm{Hg})$.

Because of the pronounced dyspnoea, lung function tests were performed, which displayed a restrictive flow pattern with normal lung mechanics and volumes, and a significant reduction in lung diffusion capacity, with a measured diffusing capacity of the lung for carbon monoxide (DLCO) of $10.21 \mathrm{ml} / \mathrm{min} /$ $\mathrm{mm} \mathrm{Hg} \mathrm{(46 \% )} \mathrm{and} \mathrm{a} \mathrm{DLCo} \mathrm{normalised} \mathrm{for} \mathrm{the}$ alveolar volume (DLCO/VA) of $1.96 \mathrm{ml} / \mathrm{min} /$ $\mathrm{mmHg} / 1$ (33\% of predicted volume).

On the basis of these findings a ventilationperfusion scan was performed that showed characteristics compatible with bilateral pulmonary thromboembolism. There was dimensional and Doppler evidence of right ventricular pressure overload. The right chamber appeared dilated and the interventricular septum deviated to the left with an estimated systolic right ventricular pressure of $70 \mathrm{~mm} \mathrm{Hg}$. A large obstructive intracardiac mass was seen in the right ventricular outflow tract, protruding through the pulmonary valve into the main pulmonary artery.

The presence of this intracardiac mass was confirmed by magnetic resonance imaging (MRI) (fig 1) and computed tomographic 


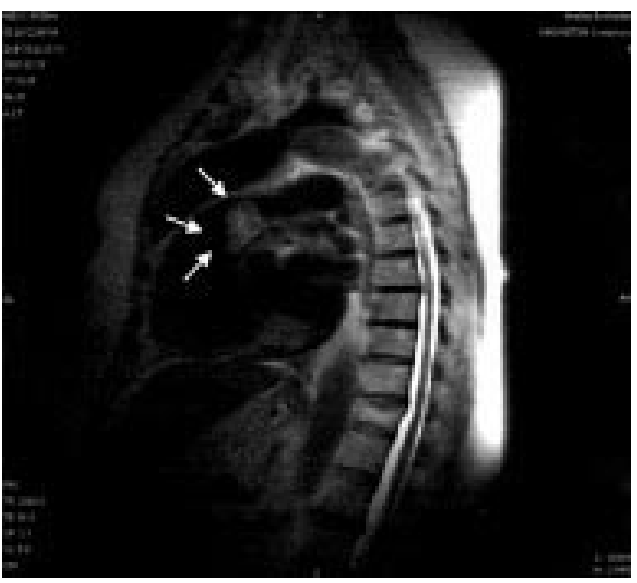

Fig 1 Magnetic resonance image on admission: sagittal planes show the tumour (arrows) in the right ventricle protruding through the pulmonary valve into the pulmonary trunk. Gadolinium injection significantly enhanced the mass.

(CT) angiography, as well as by pulmonary angiographic examination. A mass with a maximum diameter of $2.3 \mathrm{~cm}$ and $4.0 \mathrm{~cm}$ long protruded into the right ventricle through the pulmonary valve. The density of the mass was not compatible with thrombus material.

A biopsy under ultrasonic guidance and right heart catheterisation to assess the haemodynamic repercussions of the mass were not carried out as the risk of embolisation by dislodged material was considered too high.

Because symptoms progressed, surgery was deemed necessary. Macroscopic examination of the resected specimen showed a gelatinous, polypoid mass. Routine histological examination showed a tumour with a distinct myxoid stroma and densely packed cells with elongated, irregular, enlarged, and hyperchromatic nuclei. High mitotic activity was detected (31 mitotic figures per 10 high power fields in areas of high cellularity) and focal nuclear atypia was present. The tumour border consisted of fibrinoid material. Immunohistochemical staining was positive for vimentin and desmin, and negative for cytokeratine and S-100.

On the basis of the microscopical and histological findings, a high grade spindle cell sarcoma, more specifically a leiomyosarcoma, was diagnosed.

After resection extensive screening was performed, including positron emission tomography and CT of the thorax, abdomen, and brain, which excluded tumour spread or other abnormalities. One month after surgery the patient was found to be in good general health, with a significant decline in dyspnoea complaints.

As evidence for the beneficial effect of chemotherapy remains scarce and heart transplantation was considered a too aggressive approach, a wait and see approach was deemed the most favourable. The patient was advised to attend close follow up.

Seven months following resection, the patient presented with recurrent dyspnoea. At that time relapse of the tumour was detected, which warranted further palliative strategy.

\section{Discussion}

Leiomyosarcomas are an extremely small minority of sarcomas. ${ }^{24}$ The Armed Forces Institute of Pathology files ${ }^{2}$ recorded only one case among 533 primary cardiac tumours $(0.19 \%)$.

The low incidence, unpredictable course, and variable clinical presentation (table 1) of a leiomyosarcoma of the right ventricle makes the diagnosis a challenging one. In many cases cardiac masses are misdiagnosed as pulmonary thromboembolism and the correct diagnosis is often made only at the time of surgery. Presenting symptoms include dyspnoea, chest pain, and a non-productive cough. Right heart failure and valve stenosis, rhythm alterations, conduction abnormalities, haemopericardium, and sudden death have all been reported. ${ }^{5-7}$

Transthoracic and transoesophageal echocardiography are considered to be ideal and non-invasive tools for the initial diagnosis of intracardiac masses and are of great value in evaluating the haemodynamic repercussions. In addition transoesophageal echocardiographic guided transvenous biopsy appears to be a safe and valuable technique for obtaining tissue samples for histological diagnosis. ${ }^{8}$ Its

Table 1 Characteristics of seven cases of primary leiomyosarcoma of the right ventricle

\begin{tabular}{|c|c|c|c|c|}
\hline Author & $\begin{array}{l}\text { Age, sex, and clinical } \\
\text { presentation }\end{array}$ & Diagnostic procedures & Non-cardiac presentation & Treatment and survival \\
\hline Kennedy $^{22}(1967)$ & $\begin{array}{l}\text { 57, female, adenopathy } \\
\text { deterioration of general } \\
\text { condition, acute onset of } \\
\text { dyspnoea }\end{array}$ & $\begin{array}{l}\text { Negative angiography diagnosis } \\
\text { at necropsy }\end{array}$ & $\begin{array}{l}\text { Pulmonary, pleural, hepatic, } \\
\text { pancreatic metastasis on } \\
\text { necropsy }\end{array}$ & $\begin{array}{l}\text { Radio- and chemotherapy. Died } \\
17 \text { months after diagnosis of } \\
\text { adenopathy }\end{array}$ \\
\hline Bearman $^{5}(1974)$ & $\begin{array}{l}69 \text {, female, adenopathy acute } \\
\text { RHF }\end{array}$ & $\begin{array}{l}\text { Negative angiography negative } \\
\text { echography diagnosis at } \\
\text { necropsy }\end{array}$ & $\begin{array}{l}\text { Pulmonary, renal, pancreatic } \\
\text { metastasis at necropsy }\end{array}$ & $\begin{array}{l}\text { No surgery, died } 7 \text { months after } \\
\text { diagnosis of RHF }\end{array}$ \\
\hline Burnett $^{6}(1975)$ & $\begin{array}{l}60, \text { female, pericardial } \\
\text { effusions causing tamponade }\end{array}$ & $\begin{array}{l}\text { Negative angiography, negative } \\
\text { pericardial biopsy diagnosis at } \\
\text { necropsy }\end{array}$ & $\begin{array}{l}\text { Pulmonary, hepatic metastasis } \\
\text { at necropsy }\end{array}$ & $\begin{array}{l}\text { No surgery, died several months } \\
\text { after onset of symptoms }\end{array}$ \\
\hline Talley et $a l^{11}(1986)$ & 46 , male, RHF & $\begin{array}{l}\text { Positive angiography, positive } \\
\text { echography }\end{array}$ & None reported & $\begin{array}{l}\text { Partial resection, died } 10 \text { months } \\
\text { after onset of symptoms }\end{array}$ \\
\hline Egloff $e t a l^{1}(1991)$ & $\begin{array}{l}27 \text {, male, thoracic pain, } \\
\text { systolic murmur, cough }\end{array}$ & $\begin{array}{l}\text { Positive echography, positive } \\
\text { CT }\end{array}$ & $\begin{array}{l}\text { Pulmonary, pleural metastasis } \\
\text { on chest } x \text {-ray }\end{array}$ & $\begin{array}{l}\text { Complete resection. Still alive } \\
>22 \text { months after onset of } \\
\text { symptoms }\end{array}$ \\
\hline Panday $e t a l^{14}$ (1997) & $\begin{array}{l}\text { 67, male, progressive } \\
\text { dyspnoea, systolic murmur }\end{array}$ & $\begin{array}{l}\text { Positive angiography, positive } \\
\text { echography }\end{array}$ & None found & $\begin{array}{l}\text { Complete resection. Still alive }>3 \\
\text { years after onset of symptoms }\end{array}$ \\
\hline Willaert (present report) & $\begin{array}{l}\text { 70, female, thoracic pain, } \\
\text { progressive dyspnoea, systolic } \\
\text { murmur }\end{array}$ & $\begin{array}{l}\text { Positive echography, positive } \\
\text { CT and MRI, peroperative } \\
\text { diagnosis }\end{array}$ & None found & $\begin{array}{l}\text { Complete resection. Relapse } 7 \\
\text { months after surgery. Still alive } 10 \\
\text { months after onset of symptoms }\end{array}$ \\
\hline
\end{tabular}

Adapted from Egloff $e t$ al. $^{21} \mathrm{CT}$, computed tomography; MRI, magnetic resonance imaging; RHF, right heart failure. 
limitations, however, necessitate additional imaging modalities to improve preoperative diagnosis. $^{9}$

Therefore, CT and MRI play a valuable part in the diagnosis of intracardiac tumours. ${ }^{9}{ }^{10}$ In contrast to echocardiography the high quality images and multiple planes provide excellent preoperative evaluation of tumour location and possible extension into contiguous great vessels. In addition tissue characterisation can help in determining the benign or malignant origin of the neoplasm. To differentiate sarcomas from thrombi, MRI after the administration of gadolinium is a valuable aid.

Right heart catheterisation quantifies the extent of right ventricular hypertension caused by the outflow obstruction whereas right ventricular angiography allows anatomical demarcation of the mass. However, the risk of volume overload due to applying contrast media and respiratory distress caused by thrombus dislodging following the procedure should not be overlooked. ${ }^{11}$

A definitive diagnosis requires pathological examination of the tissue obtained by intravascular percutanous or surgical biopsy. High mitotic activity, cell necrosis, cellular atypia, and characteristics of invasion are associated with malignant neoplasms.

Monoclonal antibodies against cytokeratin, smooth muscle actin, desmin, vimentin, myoglobin, leucocyte common antigen, polyclonal antiserum to S-100 protein, and factor VIII can all help in the histological classification of resected sarcomas. Furthermore, they can exclude a sarcoma when there is any suspicion of a lymphoma. ${ }^{4}$ Cytokeratin (carcinoma) and S-100 (liposarcoma) immunohistochemical staining are negative for leiomyosarcoma, which are characterised by extensive expression of vimentin, desmin, and smooth muscle actin. $^{12}$

When the diagnosis of malignancy is established, surgical intervention is mandatory as the natural progression inevitably leads to irreversible heart failure, metastasis, and death. As data from large randomised trials are not available, there is no consensus on the optimal treatment strategy. Radical surgical intervention seems to be the preferred management and offers the best hope for palliation and prolonged survival ${ }^{1313-16}$; however, long term survival is not ascertained. Surgery is also indicated to obtain a definitive histological diagnosis and as a debulking procedure to remove obstructive pulmonary arterial extensions that cause outflow obstruction in non-resectable masses.

Although Babatasi and colleagues ${ }^{17}$ reported a favourable outcome after heart transplantation for a recurrent leiomyosarcoma of the left atrium, more research is needed to examine the effectiveness of this procedure and its prognosis.

The benefits of postoperative chemotherapy and radiotherapy are unknown. Some authors claim a beneficial effect of chemotherapy, ${ }^{15} 1819$ whereas others report no effect at all. ${ }^{1320}$

Burke and colleagues ${ }^{4}$ and other authors found that histological grading correlates with survival. High mitotic activity and necrosis are associated with poor survival. Right sided tumours are associated with worse survival, presumably because of late diagnosis compared with left sided tumours. The histological type of sarcoma and degree of differentiation do not affect the overall prognosis.

The overall prognosis of patients diagnosed with cardiac sarcomas is poor because the tumour is likely to have embolised extensively to one or both lungs on diagnosis. Complete resection of tumour tissue improves the survival but tumour recurrence and metastasis are frequent and the average survival rate rarely exceeds one year. ${ }^{3}$ As soon as signs of right heart failure develop, prognosis severely worsens and survival is measured in months. As can be concluded from table 1, five of the seven cases of primary leiomyosarcoma in the right ventricle show similar disappointing survival rates.

\section{CONCLUSION}

Leiomyosarcomas of the right ventricle extending across the pulmonary valve are an uncommon cause of right ventricular outflow tract obstruction. They are associated with a catastrophic prognosis. Treatment is unsatisfactory, relapse and tumour spread are frequent, and life expectancy is short. Early diagnosis is difficult but enhances the opportunity of extensive radical surgical resection, thereby prolonging survival. More research should be done to assess the optimal management of leiomyosarcomas and the role of chemotherapy, radiotherapy, and heart transplantation, and to optimise diagnostic examinations to aid rapid identification of this rare but terminal disease.

1 Silverman NA. Primary cardiac tumors. Ann Surg 1980;191:127-38.

2 McAllister HA, Fenoglio JJ. Tumors of the cardiovascular system. In: Atlas of tumor pathology, fascicle 15, series 2. Washington: Armed Forces Institute of Pathology, 1978.

3 Dein JR, Frist WH, Stinson EB, et al. Primary cardiac neoplasms: early and late results of surgical treatment in 42 patients. $\mathcal{F}$ Thorac Cardiovasc Surg 1987;93:502-11.

4 Burke AP, Cowan D, Virmani R Primary sarcomas of the heart. Cancer 1992;69:387-95.

5 Bearman RM. Primary leiomyosarcoma of the heart. Report of a case and review of the literature. Arch Pathol 1974;20: $125-8$

6 Burnett RA. Primary cardiac leiomyosarcoma with pulmonary metastases: a diagnostic problem. Scott Med f 1975;20:125-8

7 Cherrier F, Cuilliere M. Tumeurs primitives du ventricle droit. A propos de 3 observations. Ann Cardiol Angeiol (Paris) 1973;22:473-81.

8 Lynch M, Clements SD, Shanewise JS, et al. Right-sided cardiac tumors detected by transesophageal echocardiography and its usefulness in differentiating the benign from graphy and its usefulness in differentiating the ben

9 Chaloupka JC, Fishman EK, Siegelman SS. Use of CT in the evaluation of primary cardiac tumors. Cardiovasc Intervent Radiol 1986;9:132-5.

10 Shimojo M, Tsuda N, Kamihata H, et al. [Magnetic resonance imaging for cardiovascular masses]. F Cardiol 1989;19:583-92

11 Talley JD, Franch RH, Clements SD, et al. Primary right ventricular leiomyosarcoma producing outflow tract obstruction. Am Heart f 1986;112:1335-8.

12 Pucci A, Gagliardotto P, Papandrea C, et al. An unusual myxoid leiomyosarcoma of the heart. Arch Pathol Lab Med 1996;120:583-6.

13 Putnam JB Jr, Sweeney MS, Colon R, et al. Primary cardiac sarcomas. Ann Thorac Surg 1991;51:906-10.

14 Panday VR, Cramer MJ, Elbers HR, et al. Primary leiomyosarcoma of the heart presenting as obstruction to the pulmonary trunk. Am Heart f 1997;133:465-6.

15 Babatasi G, Massetti M, Agostini D, et al. [Leiomyosarcoma of the heart and great vessels]. Ann Cardiol Angeiol (Paris) 1998;47:451-8. 
16 Murphy MC, Sweeney MS, Putnam JB Jr, et al. Surgical treatment of cardiac tumors: A 25-year experience. Ann

17 Babatasi G, Massetti M, Agostini D, et al. Recurrent left-sided heart leiomyosarcoma: should heart transplantation be legitimate? F Heart Lung Transplant 1998;17:11338.

18 Pessotto R, Silvestre G, Luciani GB, et al. Primary cardiac leiomyosarcoma: seven-year survival with combined surgical and adjuvant therapy. Int $f$ Cardiol 1997;60: 91-4.
19 Rhomberg W, Grass M. [Angiosarcoma of the right atrium: local control via low radiation doses and razoxane. A case

report]. Strahlenther Onkol 1999;175:102-4.
20 Llombart-Cussac A, Pivot X, Contesso G, et al. Adjuvant chemotherapy for primary cardiac sarcomas: the IGR experience. Br f Cancer 1998;78:1624-8.

21 Egloff P, Le Metayer P, Roques X, et al. [Leiomyosarcoma of the right ventricle. Report of a case and review of the literature]. Arch Mal Coeur Vaiss 1991;84:1483-7.

22 Kennedy FB. Primary leiomyosarcoma of the heart. Cancer 1967;20:2008-12 